Journal of Student Wellbeing

November 2010, Vol. 4(1), 1-6

\title{
Is it still OK to play?
}

\author{
Michael M Patte \\ Distinguished Fulbright Scholar of Playwork and \\ Associate Professor of Education \\ Bloomsburg University \\ Bloomsburg, Pennsylvania, USA
}

\begin{abstract}
This essay provides a personal account of my experience working in a school climate of increased student and teacher accountability where play, recess and extra-curricular activities were devalued and pushed to the brink of extinction. The two works of fiction explored in the essay, Santa Claus is comin' to town and 'All summer in a day', serve as powerful metaphors exploring how devaluing play can adversely affect the overall wellbeing of children.
\end{abstract}

\section{Introduction}

Play has been a constant in the lives of American children for generations. Engaging in outdoor play provides hours of unstructured fun and allows children to experience various colours, sights and sounds that etch vivid memories and impressions. Such experiences stimulate the senses, invigorate the spirit and enliven the soul. But are opportunities for play available for children today, or are they a fading memory from the nostalgic past?

While vivid memories of play abound for grown-ups, many children today have greatly different experiences. Attitudes towards play as being frivolous, impractical and unproductive are pervasive throughout the present-day American landscape (Elkind 2007; Marano 2008; Patte 2009). To highlight, many educational settings across America are altering, reducing or eliminating time devoted to play due in part to increasing accountability for student performance on standardised tests as required by the No Child Left Behind Act 2001. Marano (2008) recently reported that some 40,000 schools across America now contribute to the suppression of curiosity and imagination through the elimination of opportunities for children to play. In a similar vein, Miller and Almon reported that kindergarten has changed radically in America during the past twenty years and that 'children today spend far more time being taught and assessed on literacy and math skills than they do learning through 
play and exploration, exercising their bodies, and using their imaginations' (2009, p. 11). For example, in the past two decades children have lost twelve hours of free time a week, including eight hours of unstructured play and outdoor activities. Even in preschool, play has taken a back seat to more structured learning activities. Just thirty years ago, 40 per cent of a typical preschool day was devoted to child-initiated play, compared with 25 per cent today (Miller \& Almon 2009).

But does reducing or eliminating time devoted to play benefit academic learning? Or can play actually improve student academic success in school? A recent study conducted by the Centers for Disease Control and Prevention examined all relevant literature on the impact on education-related outcomes of a variety of school-based playful, physical activities. Their analysis concluded that spending time engaged in such activities had either a positive effect on academic achievement or, at a minimum, did not detract from academic outcomes (US Department of Health and Human Services 2010).

In the later stages of my twelve-year teaching career I witnessed first-hand the intensification of attitudes devaluing play. At my school, many daily opportunities that once provided an outlet for both students and faculty fell by the wayside in favour of additional time for structured academic learning. Now, as a teacher at a university, many of my undergraduate students paint a similar picture to the one I experienced in their field placement sites. In their journals, comments on the lack of time devoted throughout the school day for children to play are common. The entries further expose a culture in which students and teachers are stressed. My own teaching experience and the comments from undergraduate field journals conjure up images of two works of fiction I explored as a child where play was marginalised. Both offer keen insights into the dangers of eliminating play from the lives of children.

\section{Play as illegal, immoral and unlawful}

The first work of fiction that serves as a metaphor for the present-day attitudes devaluing play is a made-for-television cartoon from 1970 titled Santa Claus is comin' to town by Romeo Muller. As a child I enjoyed watching cartoons associated with the holiday season as they helped me get into the Christmas spirit. The cartoons were exciting, entertaining and magical, much like play. As the years passed, I continued to watch the cartoons for the same reasons I did as a child. However, several years ago, as I watched Santa Claus is comin' to town, I experienced a revelation. Instead of being filled with the Christmas spirit as I had in the past, I realised that my 'teaching spirit' was dissipating as the culture of my school started to mirror the oppressive culture of Somber Town, the setting of the cartoon.

Ruling over Somber Town was a mean-spirited mayor named Burgermeister Meisterburger. One day, the Burgermeister tripped over a toy and broke his leg. Soon after the accident the Burgermeister issued an official proclamation that was displayed throughout Somber Town that read, 'Toys are hereby declared illegal, immoral, unlawful and anyone found with a toy in his possession will be placed under arrest and thrown in the dungeon. No kidding!' So the Burgermeister's police 
force rounded up all of the toys, threw them in a big pile outside the town hall, and burned them as the children watched in horror.

The children of Somber Town were devastated by the Burgermeister's proclamation, and the confiscation and destruction of their toys, and wore gloomy looks on their faces as they completed their daily chores. Then Santa Claus arrived and passed out toys to all of the children of Somber Town in defiance of the law. The gloomy faces were replaced with bright smiles as the children filled the streets and played. I witnessed similar transformations in my elementary school children as they came bounding outside to engage in unstructured, outdoor, free play; their eyes bright, their faces beaming with excitement. In the fictional cartoon, Santa was wise and brave enough to defy the law banning toys in Somber Town. But who among us today is wise and brave enough to alter the hearts and minds of those marginalising play in our society? It appears that, just as Santa Claus is revered in our childhood and then viewed as a figment of our imaginations as we mature, so too are our modern views of play and its importance in the lives of children.

Like the Burgermeister's proclamation banning toys from Somber Town, and its dramatic effect on the children, the passage of the No Child Left Behind Act 2001 undermined positive attitudes towards play in my elementary school and others throughout Pennsylvania in favour of attitudes stressing improved student achievement (Patte 2009). Santa Claus is comin' to town has a happy ending, as the law banning toys is eventually forgotten. However, as the debate about the importance of play in the lives of children continues at my former elementary school and at the undergraduate field sites, many students and teachers today appear to reside in real-life Somber Towns.

\section{Play as the human spirit personified}

Whereas Santa Claus is comin' to town served as a metaphor for present-day attitudes devaluing play, the second work of fiction, 'All summer in a day', speaks about play deprivation and its impact on the human spirit. 'All summer in a day' by Ray Bradbury (1959) is a science fiction story I first read as a child. As I shared the story several years ago with my elementary school children, the content of the story, which seemed so unimaginable, appeared to be unfolding right before my eyes.

This story takes place in an underground third grade classroom on the planet Venus. All of the children were nine years old and all had spent their entire lives on Venus, except for one child named Margot who grew up on Earth and moved to Venus with her family. While on Earth, Margot experienced the warmth and wonders of the sun daily, but for the children born on Venus the sun appeared for just two hours every seven years. During this precious time frame the children played outside and explored the foreign world that lay before them.

So as the children waited for the sun to appear they read stories about the sun, and wrote essays and poems about it. Margot's poem read, 'I think the sun is a flower. That blooms for just one hour.' As you can imagine, the children native to Venus were jealous of Margot because she remembered the sun vividly. Their disdain for Margot boiled over and, as the teacher stepped out of the class, they surged about 
her, seized her and locked her in a closet just as the rain began to dissipate. Upon the teacher's return, the rest of the children readied for their first recess in seven years and a monumental transformation occurred. Bradbury describes the experience in vivid detail:

The children lay out, laughing on the jungle mattress, and heard it sigh and squeak under them, resilient and alive. They ran among the trees, they slipped and fell, they pushed each other, they played hide-and-seek and tag ... They looked at everything and savored everything. Then, wildly, like animals escaped from their caves, they ran and ran in shouting circles. They ran for an hour and did not stop running. (1959, p. 3)

Then, as quickly as the sun had appeared, it was gone. The reaction was immediate and unmistakable as described by Bradbury.

And then in the midst of their running one of the girls wailed. In the center of her cupped hand was a single raindrop. She began to cry looking at it. They turned and started to walk back toward the underground house, their hands at their sides, their smiles vanishing away. (p. 3)

'All summer in a day' ends tragically on two fronts. First, Margot's spirit was crushed unjustly at the hands of her classmates and kept from experiencing the one thing she most looked forward to: seeing, feeling and playing in the sun. Although the children from my former elementary school and those attending the undergraduate student field sites were not trapped in an underground classroom, or serving a seven year sentence trapped inside of the school, their spirits were just as devastated as Margot's each day they were deprived of time to play outside (Patte 2009).

Second, the children had to suppress all of the joy and sensory experiences associated with exploring the natural world through playing outside, a condition identified by Richard Louv (2005) as 'nature deficit disorder'. It seems that today more and more children spend increasing amounts of time inside peering outside for a look at the sun (Marano 2008). And while there are many powerful forces challenging the inclusion of play in the daily landscapes of life at school, the negative forces at home are just as daunting. Many parents are fearful for the safety of their children in light of high profile abduction cases witnessed on nightly news broadcasts. This 'stranger danger' concern is burned into the psyche of many modern day parents.

\section{Implications}

What are the implications of eliminating play from the school day? One possible implication is an increase in inappropriate student behaviour. A 2009 study by Barros, Silver and Stein found that providing daily play breaks for children in excess of 15 minutes was associated with better teacher ratings of class behaviour.

In addition, eliminating play from the lives of children impairs the development of social skills. Jambor (1999) recognised the playground as one of the few places where children can actively confront, interpret and learn from meaningful social 
experiences. When children organise their own games, they exhibit a wide range of social competencies.

Recent evidence from the field of neuroscience (Panksepp, Burgdorf, Turner \& Gordon 2003) suggests that the disorder known as attention deficit hyperactivity disorder (ADHD), which affects 6 to 16 per cent of American children, may result not from faulty brain wiring or chemistry but from a restriction on the urge to play. Panksepp (2002) has found that vigorous bouts of unstructured social play may be the best treatment for reducing the impulsive behaviours that characterise ADHD.

Further, eliminating play impedes the physical health of children. Nearly one third of children and teens are overweight or obese. According to the US Department of Health and Human Services (2008) daily physical activity in the form of play helps control weight, builds lean muscle, reduces fat, and contributes to a healthy functioning cardiovascular system, hormonal regulatory system and immune system; promotes strong bone, muscle and joint development; and decreases the risk of obesity.

Finally, the disappearance of play crushes the most enduring quality of our children: their human spirit. Brian Sutton Smith summed up this idea poignantly: 'the opposite of play - if redefined in terms which stress its reinforcing optimism and excitement - is not work, it is depression' (1999, p. 254). In conclusion, as a former elementary school teacher, I will always remember the sheer joy of the screaming voices, the beaming faces and the wild-eyed expressions of children engrossed in their unstructured outdoor play. However, as a university professor, just as striking is the deafening silence of the abandoned playgrounds that I witness all too often. Unfortunately, the landscape for many American children today mirrors that of Somber Town and the planet Venus where the wonders of self-initiated, outdoor play are no more than a faded memory from the distant past.

\section{References}

Barros, RM, Silver, EJ \& Stein, REK 2009, 'School recess and group classroom behavior’, Pediatrics, vol. 123, pp. 431-436.

Bradbury, R 1959, ‘All summer in a day’ in R Bradbury, A medicine for melancholy and other stories, Doubleday \& Co, New York.

Elkind, D 2007, The power of play: how spontaneous, imaginative activities lead to happier, healthier children, Da Capo Press, Cambridge, MA.

Jambor, T 1999, 'Recess and social development', Earlychildhood News, http://www.earlychildhoodnews.com/earlychildhood/article_view.aspx?Artic leID=39 (accessed 10 August 2010).

Louv, R 2005, Last child in the woods: saving our children from nature-deficit disorder, Algonquin, New York. 
Marano, HE 2008, A nation of wimps: the high cost of invasive parenting, Broadway, New York.

Miller, E \& Almon, J 2009, Crisis in the kindergarten: why children need to play in school, Alliance for Childhood, College Park, MD.

Muller, R 1970, Santa Claus is comin’ to town, Golden Books Publishing Company, New York.

Panksepp, J, Burgdorf, J, Turner, C \& Gordon, N 2003, 'Modeling ADHD-type arousal with unilateral frontal cortex damage in rats and beneficial effects of play therapy', Brain and Cognition, vol. 52, no. 1, pp. 97-105.

Panksepp, J 2002, 'ADHD and the neural consequences of play and joy: a framing essay’, Consciousness \& Emotion, vol. 3, no. 1, pp. 1-6.

Patte, MM 2009, 'The state of recess in Pennsylvania elementary schools: a continuing tradition or a distant memory?' in Play and culture studies, transactions at play, vol. 9, ed. C Dell-Clark, University Press of America, Lanham, MD, pp. 147-165.

Sutton Smith, B 1999, 'Evolving a consilience of play definitions: playfully', in Play and Culture Studies, vol. 2, ed. S Reifel, Ablex, Stamford, CT, pp. 239256.

US Department of Health and Human Services, Centers for Disease Control and Prevention 2010, The association between school-based physical activity, including physical education, and academic performance, US Department of Health and Human Services, Atlanta, GA.

US Department of Health and Human Services 2008, 2008 physical activity guidelines for Americans, US Department of Health and Human Services, Washington, DC, http://www.health.gov/paguidelines/guidelines/default.aspx (accessed 10 August 2010). 